\title{
Revisiting Epistemic Injustice in the Context of Agency
}

\author{
Lubomira Radoilska $^{1}$ (iD
}

Accepted: 26 October 2020 / Published online: 29 October 2020

(C) The Author(s) 2020

\begin{abstract}
What makes an injustice epistemic rather than ethical or political? How does the former, more recent category relate to the latter, better-known forms of injustice? To address these questions, the papers of this Special Issue investigate epistemic injustice in close connection to different conceptions of agency, both epistemic and practical.
\end{abstract}

Keywords Agency - Generics · Epistemic attention deficit · Epistemic disempowerment Epistemic injustice $\cdot$ Epistemology of ignorance $\cdot$ Explanatory injustice $\cdot$ Logocentrism . Objectification $\cdot$ Violability

What makes an injustice epistemic rather than ethical or political? How does the former, more recent category relate to the latter, better-known forms of injustice? To address these questions, the papers of the Special Issue investigate epistemic injustice in close connection to different conceptions of agency, both epistemic and practical. The underlying ambition is to bring together and redirect a number of ongoing debates. Some of the articles challenge the current understanding of what constitutes epistemic injustice and how various kinds of agency might be involved. Others, by contrast, revisit from a fresh angle fundamental concepts, such as knowledge, epistemic agency and democratic legitimacy. They all make an original contribution to philosophy by reconnecting state-of-the-art work across several areas of practical and theoretical philosophy, which have developed in relative isolation from each other.

To forge a new direction in the analysis of epistemic injustice, the selected papers engage in close dialogue with the two main theoretical frameworks, within which the topic has been addressed so far. The first is that of virtue epistemology. Building on Fricker (Fricker 2007), which introduced the topic into mainstream analytic philosophy, harm inflicted to individuals in their capacity of knowers, believers, inquirers and/or communicators is the distinctive feature of epistemic injustice. Its different kinds, e.g. testimonial and hermeneutical are best understood in terms of criticisable dispositions, such as indifference. By contrast, epistemic justice is associated with the active exercise of specific intellectual virtues including openmindedness, well-placed trust and intellectual courage. The virtue-epistemic framework is

Lubomira Radoilska

L.V.Radoilska@kent.ac.uk

1 Department of Philosophy, University of Kent, Canterbury, Kent, UK 
well-suited to track the individual contributions to just and unjust epistemic relations and outcomes. At the same time, however, it is open to criticism for underestimating the structural and systemic underpinnings of epistemic injustice, which make it entrenched, insidious and difficult to overcome. To resolve these issues, a second framework has been developed within political philosophy. Drawing on insights from feminism and critical race theory, this framework not only helps shed light onto institutional contexts and mechanisms that often subvert both individual and collective efforts to achieve epistemic justice. It also aims to identify viable strategies for minimising and resisting epistemic injustice (Medina 2013; Pohlhaus Jr. 2017). Yet, the increased awareness of structural issues expressed in distributive terms has brought its own methodological difficulties, such as disconnect between the personal, social and subpersonal level analysis of the phenomenon.

The contributions to this Special Issue help address specific concerns that arise from some applications of these two frameworks, while at the same time building on many of their insights. A major strength of this collective project is its reflective focus on the relationship between epistemic and other kinds of agency - moral, political, pragmatic, institutional, etc. in the creation of, but also resistance to epistemic injustice. A related advantage is its critical attention to the ways in which the conditions of epistemic injustice might affect the nature and scope of different dimensions of agency, putting to the test underlying assumptions about activity and passivity in our mental lives.

In their respective papers, Veli Mitova and Leonie Smith and Alfred Archer identify and explore two new categories of epistemic injustice, explanatory injustice and epistemic attention deficit. Both derive from identity prejudice. The former category consists in a wrongful and disempowering attribution of reasons to agents. When such attribution occurs, affected agents are denied - inappropriately - authority over beliefs and actions of theirs. Such beliefs and actions get explained away as resulting from what these agents are supposed to be, in the light of some identity prejudice. Their self-understanding as agents - both epistemic and practical - is treated as confused, unreliable and irrelevant by default. By contrast, the latter category, epistemic attention deficit wrongs agents in their capacity of contributors to shared practices where knowledge is created and transmitted. As a result, affected agents are deprived of effective means to influence what others believe on matters of shared importance. Furthermore, challenging the prejudicial terms on which communication proceeds remains out of their reach.

The papers by Aidan McGlynn and Martina Rosola and Federico Cella expand on the notion of testimonial injustice in complementary ways. The first revisits an important debate, about the primary form that this phenomenon takes. The two contesters in the literature epistemic objectification and epistemic othering - are contrasted and compared in the light of Martha Nussbaum's cluster analysis of objectification. As McGlynn compellingly argues, the notion of violability rather than that of inertness offers a better insight into the key role that objectification plays in undermining the testimonial standing of capable epistemic agents. This picture acknowledges that epistemic othering - a process whereby someone's epistemic agency is partly recognised to be more effectively subverted - can be the source of distinctly epistemic harms. These harms, however, are not at the heart of testimonial injustice.

The second paper explores how testimonial injustice might be caused directly by the use of generics, sentences that express generalisations about a category as such or about its members but do not specify how widespread the predicated property is across the category. Examples include propositions, such as 'Apples are sweet' or 'Women are weak leaders'. The ensuing vagueness coupled with an unspoken assumption that predication is practically universal 
within the category offers fertile ground for the inadvertent development of essentialising beliefs about its members. As our first example - predicating sweetness to apples - indicates, this upshot could be innocuous on many occasions. Yet, when generics apply to social categories where identity prejudice is already at work as the case is in our second example, they would tend to both corroborate and amplify this prejudice. As a consequence, members of the affected social category will be subject to diminished credibility in line with the prejudicial essentialising beliefs that generics channel.

The under-explored implications of mainstream conceptual frameworks for particularly vulnerable categories of agents are considered in detail by the following pair of papers. One of them, by Amandine Catala, critically examines the underlying assumption that epistemic agency and therefore epistemic justice are fundamentally about propositional knowledge and verbal communication. According to Catala, this focus proves unduly exclusive to the point of generating a meta-level epistemic injustice. This is because core exercises of epistemic agency, including practical, affective and embodied knowing slip under this propositional radar. As a result, agents are left unprotected from epistemic harms in these domains. This outcome is particularly disturbing since non-propositional kinds of knowing are often the main, if not the only, mode of epistemic agency for some vulnerable groups and individuals. As a case in point, Catala considers knowers and communicators with profound intellectual disabilities on the mainstream logocentric model of epistemic agency and epistemic justice that she criticises, such knowers and communicators would remain invisible.

Like Catala, Andrew Fletcher and Jeremy Clarke look into epistemic wrongs that derive from privileging particular modes of knowing over others. Their argument rests on a detailed case study of an interdisciplinary partnership between a local National Health Service Trust, the social services and the private sector. Their common task was to support members of the community diagnosed with anxiety and depression who are also out of work. Building on the notion of pathocentric epistemic complex that was put forward in Kidd and Carel (Kidd and Carel 2019), Fletcher and Clarke identify and analyse a detrimental mismatch between the understandings of expertise and experience in frontline services and upper-level service management and commissioning. While participating frontline service providers unduly privilege formal learning and clinical qualifications over knowing by personal experience, this same clinical perspective is systematically undervalued by the Programme's managers and commissioners who see it as secondary to efficiency considerations.

Th two concluding papers of the Special Issue turn to epistemic injustice in the political sphere. In her contribution, Magali Bessone offers an insightful case study of two opposing anti-racist positions in France. According to the first, publicly dominant position, the anti-racist agenda is best served by eliminating all refences to race in public discourse. According to the second, critical-theoretic position, racial concepts are indispensable epistemic tools that enable us to articulate and seek to redress race-related inequalities and wrongs that would otherwise remain undetected. Building on a contrastand-compare analysis of these two positions, Bessone demonstrates how and why the ideal of a colour-blind republic that underpins the first, race-eliminative approach derives from a recalcitrant epistemology of white ignorance (see (Mills 2007)). This epistemology results in deep hermeneutical epistemic injustice, the stifling of alternative epistemic resources that would allow racialised groups and individuals to understand and combat the social wrongs that they experience. By contrast, the second, critical-theoretic approach is an epistemology of resistance that aims at the development of much-needed resources for the epistemic empowerment of the affected groups and individuals. 
Federica Liveriero makes a case for revisiting a fundamental normative concept in political theory, that of democratic legitimacy. According to Liveriero, systematic forms of epistemic injustice undermine directly the legitimacy of political institutions. This is because persistent patterns of epistemic injustice lead to the epistemic disempowerment of the affected groups and individuals as political agents. Their reflective ability to contribute to the democratic process is severely curtailed. As a consequence, the ideal of co-authorship on which democratic legitimacy is premised becomes difficult to implement. Liveriero articulates several institutional strategies that can help reverse the underlying process of democratic de-legitimation through systemic epistemic injustice. At the heart of this exciting proposal lies the idea of a dynamic community of epistemic trust where previously marginalised agents would receive due consideration.

Acknowledgements Earlier drafts of all selected papers were presented at the 2019 SWIP-UK Conference on 'Epistemic Injustice and Agency' held at the University of Kent, UK. This event as well as my guest-editorial work toward this Special Issue were supported by a British Academy Newton Advanced Fellowship Award, Ref.: NAFR1180082. I would also like to thank all Conference Participants and Special Issue Reviewers for their generous, constructive and detailed comments which were instrumental to the successful completion of this collective project.

Funding Research on this project was supported by a British Academy Newton Advanced Fellowship Award: NAFR1180082.

\section{Compliance with Ethical Standards}

\section{Conflict of Interest None.}

Open Access This article is licensed under a Creative Commons Attribution 4.0 International License, which permits use, sharing, adaptation, distribution and reproduction in any medium or format, as long as you give appropriate credit to the original author(s) and the source, provide a link to the Creative Commons licence, and indicate if changes were made. The images or other third party material in this article are included in the article's Creative Commons licence, unless indicated otherwise in a credit line to the material. If material is not included in the article's Creative Commons licence and your intended use is not permitted by statutory regulation or exceeds the permitted use, you will need to obtain permission directly from the copyright holder. To view a copy of this licence, visit http://creativecommons.org/licenses/by/4.0/.

\section{References}

Fricker M (2007) Epistemic injustice: power and the ethics of knowing. Oxford University Press, Oxford

Kidd IJ, Carel H (2019) Pathocentric epistemic injustice and conceptions of health. In: Sherman B, Goguen S (eds) Overcoming epistemic injustice: social and psychological perspectives. Rowman and Littlefield, London, pp 153-162

Medina J (2013) The epistemology of resistance: gender and racial oppression, epistemic injustice and resistant imaginations. Oxford University Press, New York

Mills C (2007) White ignorance. In: Sullivan S, Tuana N (eds) Race and epistemologies of ignorance. State University of New York Press, Albany, pp 11-38

Pohlhaus G Jr (2017) Varieties of epistemic injustice. In: Kidd IJ, Medina J, Pohlhaus G Jr (eds) The Routledge Handbook of Epistemic Injustice. Routledge, Abingdon, pp 13-26

Publisher's Note Springer Nature remains neutral with regard to jurisdictional claims in published maps and institutional affiliations. 